Europe's Journal of Psychology 3/2009, pp. 1-2

www.ejop.org

\title{
The Psychology of Specialization and Specialization in Psychology
}

\author{
By Fathali M. Moghaddam \\ Georgetown University
}

Some years ago I committed blatant heresy by publishing a book that questions one of the sacred beliefs of the modern world; namely, that specialization is necessarily beneficial. This belief has become sacred because it is derived from two lines of argument, each of which is independently taken for granted as received wisdom. The first line of argument derives from the ideas of Adam Smith (1723-1790), particularly as set out in The Wealth of Nations. By increasing divisions of labor, Smith argued, workers could become more productive, "The division of labour... so far as it can be introduced, occasions, in every art, a proportional increase of the productive powers of labour." The second line of argument is derived from an even more illustrious source, Charles Darwin's (1809-1882) monumental scientific treatise on the Origin of Species. The theory of evolution seems to imply that specialization is necessary to maximize the utilization of environmental resources, find 'vacant spaces', and increase survival chances. Taken together, Smith and Darwin seem to present increasing specialization as an inevitable and necessary path to increasing production and improving survival opportunities.

In The Specialized Society (1997), I argued that specialization in areas such as human education and research should not be designed according to purely materialist criteria, such as 'productivity'. Education and research must give priority to training the 'whole person' and to the individual as a unique, independent, complete entity, rather than to shaping the individual as 'a specialized part of a whole'. I continue to wonder, was I being too idealistic? The sub-title of The Specialized Society is The Plight of the Individual in an Age of Individualism, and I wonder if I was being too idealistic to question and spotlight that plight?

Graduate education seems to be forcing students into narrower lines of research, which if they are successful will be published in ever more specialized journals. In 
every major domain of research, there are now ten and in some instances twenty or forty or fifty times more specialized journals than there were several decades ago. I used to be able to keep up with the half a dozen or so journals in my academic area, but now there are dozens and dozens of specialized journals publishing on topics 'in my field' and I do not even keep up with the titles of papers being published. Is this trend beneficial? Does this trend represent progress? Perhaps it does in a way, but these are questions we seldom discuss, because we are all hurrying to publish the next paper in our increasingly specialized journals. We do not have time for such 'large' questions, we are too deeply immersed in our specialized lines of research to be able to look about and critically examine the larger picture and our own development as whole persons. This continues to be the plight of the individual in an age of individualism.

About the author:

Fathali Moghaddam is Professor, Department of Psychology and Director, Conflict Resolution Program, Department of Government, at Georgetown University in Washington. He is also Senior Fellow at the Center for Interdisciplinary Policy, Education and Research on Terrorism. Prof. Moghaddam has been published extensively on the psychology of intergroup conflict, subjective justice, radicalization, and terrorism. He was awarded the Lifetime Achievement Award in 2007 by the American Psychological Association's Society for the Study of Peace, Conflict and Violence. Among his publications: The specialized society: The plight of the individual in a age of individualism (1997); Social psychology: Exploring universals across cultures (1998); From the Terrorists' Point of View: What They Experience and Why They Come to Destroy (2006) and Multiculturalism and Intergroup Relations: Psychological Implications for Democracy in Global Context (2008). 